\title{
Three-Dimensional Cell Culture and Tissue Engineering in a T-CUP (Tissue Culture Under Perfusion)
}

\author{
NICHOLAS E. TIMMINS, Ph.D., ARNAUD SCHERBERICH, Ph.D., JENNIFER-ANNIKA FRÜH, B.Sc., \\ MICHAEL HEBERER, M.D., IVAN MARTIN, Ph.D., and MARCEL JAKOB, M.D.
}

\begin{abstract}
The aim of this study was to develop and validate a simple and compact bioreactor system for perfusion cell seeding and culture through 3-dimensional porous scaffolds. The developed Tissue Culture Under Perfusion (T-CUP) bioreactor is based on the concept of controlled and confined alternating motion of scaffolds through a cell suspension or culture medium, as opposed to pumping of the fluid through the scaffolds. Via the T-CUP, articular chondrocytes and bone marrow stromal cells could be seeded into porous scaffolds of different compositions and architectures (chronOS ${ }^{\mathrm{TM}}$, Hyaff ${ }^{\circledR}-11$, and Polyactive ${ }^{\mathrm{TM}}$ ) at high efficiency (greater than $75 \%$ ), uniformity (cells were well distributed throughout the scaffold pores), and viability (greater than 97\%). Culture of articular chondrocytes seeded into 4-mm thick Polyactive ${ }^{\mathrm{TM}}$ scaffolds for 2 weeks in the T-CUP resulted in uniform deposition of cartilaginous matrix. Cultivation of freshly isolated human bone marrow nucleated cells seeded into ENGipore ceramic scaffolds for 19 days in the T-CUP resulted in stromal cell-populated constructs capable of inducing ectopic bone formation in nude mice. The T-CUP bioreactor represents an innovative approach to simple, efficient, and reliable 3D cell culture, and could be used either as a model to investigate mechanisms of tissue development or as a graft manufacturing system in the context of regenerative medicine.
\end{abstract}

\section{INTRODUCTION}

$\mathbf{T}$ HE ABILITY to cultivate cells reliably in a 3-dimensional (3D) environment is an important step for the development of physiological in vitro models to investigate mechanisms of cell growth, differentiation, and tissue development, as well as for the generation of implantable tissue constructs in the context of regenerative medicine. Approaches employing cell seeding and culture within porous 3D scaffolds are now commonplace; however, typical methodologies and technologies suffer from several limitations, especially if the target construct is a few millimetres in thickness.

Under static conditions it is generally difficult to distribute cells within the scaffold with adequate efficiency and uniformity, and subsequently supply them with sufficient nutrients to support growth, ${ }^{1-5}$ function, and viability throughout the full thickness of the construct. ${ }^{2,3,5-7}$. Stirred systems represent an improvement as compared to static cultures, ${ }^{2,3,8}$ but uniform cell distributions remain difficult to be achieved, ${ }^{3,9}$ and mass transfer limitations continue to restrict the thickness of tissue that can be generated. ${ }^{8-10}$ In addition, low cell seeding efficiencies have been reported using static or stirred cultures ${ }^{2,6,11,12}$ : this is a critical issue for many tissue engineering applications, where only a limited amount of cells is available. Relatively uniform distributions of extracellular matrix were achieved by application of dynamic laminar flow within Rotary Cell Culture Systems (RCCS). ${ }^{13}$ While in this approach diffusion restrictions are relaxed and good mixing is achieved, the RCCS is not well suited for cell seeding into porous scaffolds, and construct size is ultimately still diffusion limited.

To overcome the limitations of static and stirred cultivation systems, direct perfusion through the scaffold pores

Tissue Engineering, Laboratory 405, Departments of Surgery and of Research, Hebelstrasse 20, CH-4031 Basel, Switzerland. 
of a cell suspension for cell seeding, and of culture medium for subsequent culture, is becoming increasingly popular. Direct perfusion systems have been reported to achieve high cell seeding efficiencies at uniform distributions, maintaining cell viability within large constructs for extended periods of time. ${ }^{14-18}$ Flow-induced shear stresses in perfusion systems were also used to improve osteoprogenitor cell proliferation and differentiation, ${ }^{19}$ and to study fundamental aspects of tissue development in vitro in the presence of controlled physical conditioning. ${ }^{20}$ However, existing perfusion bioreactor systems tend to be complicated in design, difficult to operate, inflexible, or inefficient. Complicated pump and tubing arrangements, unreliable connectors and fittings, fixed geometries, limited capacity, and the need for skilled operators to reduce the risk of leaking and contamination are among a number of limitations, related to the need of moving fluid through fixed paths.

It occurred to us that a simplified perfusion reactor configuration, possibly overcoming such limitations, could be based on an alternative principle, whereby scaffolds are moved through the fluid, as opposed to the fluid being pumped through the scaffolds. Thus, the aim of this study was to develop and validate a bioreactor for perfusion cell seeding and culture through 3D porous scaffolds, based on the concept of controlled motion of scaffolds through a cell suspension or culture medium. The performance of such a system was assessed with regard to cell seeding efficiency and uniformity, operational reliability, support and maintenance of viable cell populations over extended culture periods, and ability to generate uniform tissue constructs of clinically relevant size (i.e., a few millimeter thickness), using a variety of scaffold compositions and pore architectures.

\section{MATERIALS AND METHODS}

\section{Scaffolds and scaffold preparation}

We used scaffolds of various compositions and architectures. Polyactive ${ }^{\mathrm{TM}}$ foams (IsoTis N.V., NL) were made of poly(ethylene glycol terephthalate) (PEGT):poly(butylene terephthalate) (PBT) in a ratio of 55:45, with $300 \mathrm{MW}$ PEGT and a porosity of $75 \%$. Hyaff $^{\circledR}-11$ nonwoven meshes (Fidia Advanced Biopolymers, Italy) were made of esterified hyaluronic acid, with a porosity of $93 \%$. ChronOS ${ }^{\mathrm{TM}}$ (Synthes, $\mathrm{CH}$ ) and ENGipore (Fin-Ceramica Faenza, I) ceramic foams were made of respectively $\beta$-tricalcium phosphate, with a porosity of $60 \%$, and hydroxyapatite, with a porosity of $83 \%$.

Polyactive $^{\mathrm{TM}}$, Hyaff ${ }^{\circledR}-11$, ChronOS $^{\mathrm{TM}}$, and ENGipore scaffolds were used as $4 \mathrm{~mm}$ thick $\times 8 \mathrm{~mm}$ diameter cylinders. ChronOS ${ }^{\mathrm{TM}}$ scaffolds were also available in the form of granules (1.4-2.4 mm). Polyactive ${ }^{\mathrm{TM}}$ scaffolds were sterilized and hydrated via graded ethanol concentrations in milliQ water, followed by overnight soaking in culture medium. All other scaffolds were available presterilized from the manufacturer.

\section{Cell isolation and culture medium}

Bovine articular chondrocytes (AC). Femoral condyle cartilage of bovine calves was digested for $22 \mathrm{~h}$ in $0.15 \%$ type II collagenase (Worthington) at $37^{\circ} \mathrm{C}$. Isolated cells were plated overnight on tissue culture plastic in highglucose Dulbecco's modified Eagle's medium (DMEM; Invitrogen) with typical culture supplements (i.e., $10 \%$ fetal bovine serum [FBS], $1 \mathrm{mM}$ sodium pyruvate, $10 \mathrm{mM} \mathrm{N-2-}$ hydroxyethylpiperazine- $N$-2-ethanesulfonic acid (HEPES), $2 \mathrm{mM}$ L-glutamine, $100 \mathrm{U} / \mathrm{mL}$ of penicillin, and $100 \mu \mathrm{g} / \mathrm{mL}$ of streptomycin, all from Invitrogen), and subsequently stored in liquid nitrogen. AC were expanded for a maximum of 6 passages in the above medium further supplemented with $1 \mathrm{ng} / \mathrm{mL}$ transforming growth factor- $\beta$ (TGF $\beta-1$; R\&D Systems Europe) and $5 \mathrm{ng} / \mathrm{mL}$ of fibroblast growth factor-2 (FGF-2; R\&D Systems Europe), as previously described. ${ }^{21}$ The same medium was used during bioreactor culture.

Human bone marrow stromal cells (BMSC). Bone marrow aspirates were obtained from the iliac crest of healthy patients during routine orthopaedic surgical procedures, in accordance with local ethical regulations and with informed patient consent. Nucleated cells were isolated by Histopaque (Sigma) density centrifugation and then either plated onto tissue culture plastic (for expansion before seeding experiments), or transferred directly to the bioreactor. Cells for seeding experiments were expanded for a maximum of 5 passages in medium consisting of $\alpha$-minimum essential medium $(\alpha-\mathrm{MEM})$ with the above defined culture supplements to which $5 \mathrm{ng} / \mathrm{mL}$ of FGF-2 were further added.

\section{The Tissue-Culture Under Perfusion (T-CUP) bioreactor}

The T-CUP bioreactor employs the principle of alternating perfusion ${ }^{15}$ to distribute cells within scaffolds and maintain nutrient supply. A peculiar feature of the system is the fact that perfusion is generated by the motion of scaffolds through the fluid (i.e., a cell suspension or culture medium), with the only possible path for the fluid being through the scaffold pores.

In the assembled bioreactor, scaffolds (Fig. 1a) were located in a scaffold housing of customizable geometry fabricated from polytetrafluoroethylene (PTFE) (Figs. 1b and 5a), which was mounted into a dual-upper reactor cup, made of stainless steel (SS316L) (Fig. 1c). Unless otherwise stated, the scaffold housing was made to accommodate 6 scaffolds in the shape of $8 \mathrm{~mm}$ diameter $\times 4 \mathrm{~mm}$ thick cylinders. In some experiments, the scaffold housing was in the form of a basket, in which granular porous scaffolds were irregularly compacted. The dual-upper cup was mounted over the lower cup, also made of stainless steel (Fig. 1d), creating a closed chamber that was dynamically sealed with an O-ring (Fig. 1e). Internal surfaces were either coated with a $30-\mu \mathrm{m}$ layer of fluoroethylene propylene (FEP) or electropolished 

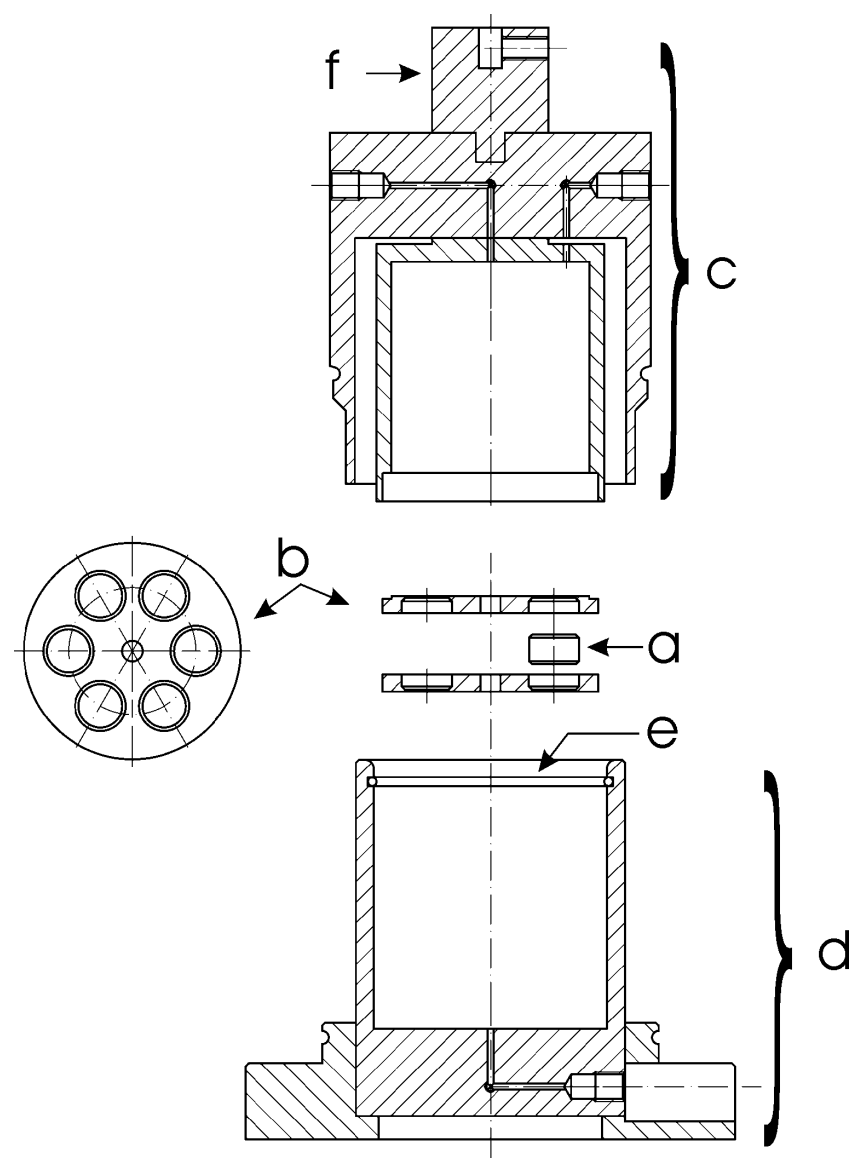

FIG. 1. Cross section of T-CUP bioreactor. (a) Scaffold, (b) scaffold housing, (c) dual upper cup assembly, (d) lower cup assembly, (e) O-ring, (f) drive shaft interface.

to ensure that cells would not adhere to the bioreactor and to improve cleanability. FEP coating or electropolishing were selected after preliminary experiments made with other materials, which either did not prevent cell attachment (i.e., polycarbonate, polysulfone) or were progressively deformed by repeated autoclaving (i.e., PTFE, polyetheretherketone).

The interface region between the two reactor cups and the dynamic seal was isolated from the external environment by a flexible bellows (not shown in Fig. 1). The assembled reactor vessel was mounted into a drive frame to which a stepper motor was attached (L4218L1806-M6X1, Nanotec GmbH \& Co. KG, Munich), and by means of the drive interface (Fig. 1f), the drive shaft was affixed to the top of the upper reactor cup. A fully assembled system is shown in Fig. 2.

On operation of the stepper motor, the upper reactor cup is driven along its vertical axis in alternating directions. Consequently, scaffolds located in the scaffold housing move through the fluid (i.e., cell suspension or culture medium) in the lower cup, which is forced to pass through the pores of the scaffolds. In particular, on the downward stroke compression pushes medium through the pores, and on the upward stroke expansion of the chamber reverses the flow direction (see

FIG. 2. Fully assembled T-CUP bioreactor vessel and drive unit.

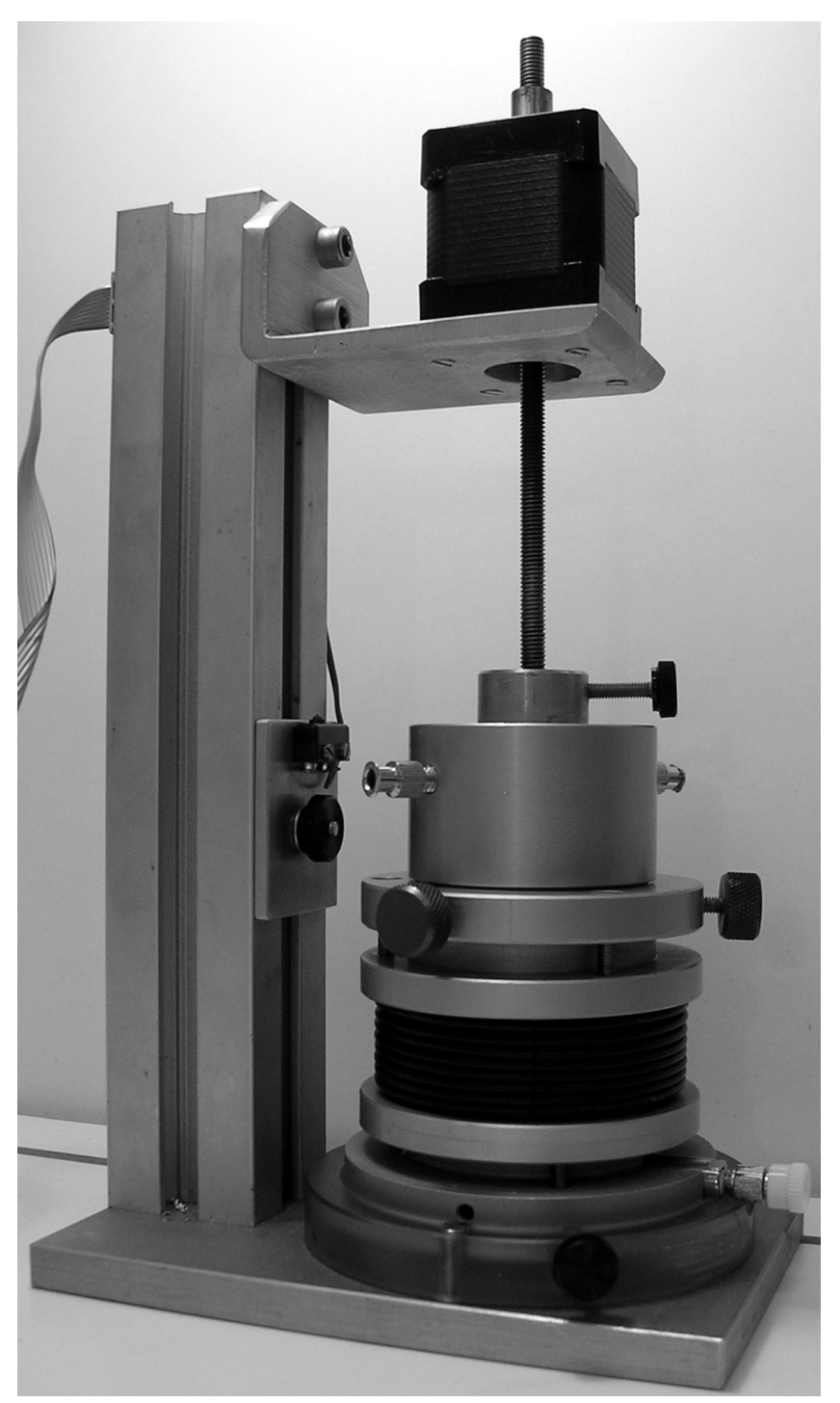

Fig. 3). Gas exchange occurs as a consequence of this cyclic compression and expansion via a port on the dual-upper cup fitted with a $0.2-\mu \mathrm{m}$ sterile PTFE filter (Acro37, PALL).

\section{Seeding uniformity}

The bioreactor vessel was sterilized by autoclaving, and assembled with sterile scaffolds in a biological safety cabinet. Twenty-five to thirty-five milliliters of seeding cell suspension at the desired density (typically in the range of $1 \times 10^{6}$ $-1 \times 10^{7}$ cells/scaffold) were introduced into the lower reactor cup, and the reactor vessel was then assembled and mounted in the drive frame. The reactor was operated for approximately $15 \mathrm{~h}$ at velocities from 0.1 to $3 \mathrm{~mm} / \mathrm{s}$, after which 3-(4,5-dimethylthiazol-2-yl)-2,5-diphenyltetrazolium bromide (MTT) solution was added to a final concentration of $0.05 \mathrm{mg} / \mathrm{mL}$ and perfused for a further $3 \mathrm{~h}$. Scaffolds were 


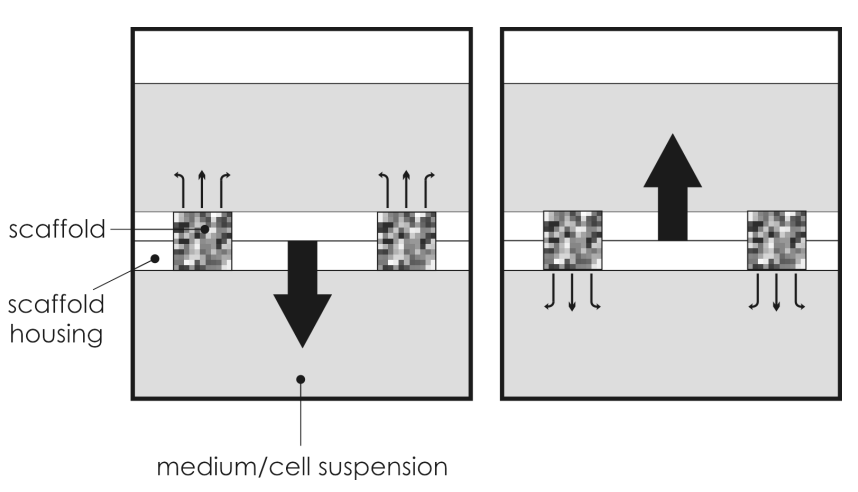

FIG. 3. Perfusion of medium through porous scaffolds in the T-CUP bioreactor is induced by movement of the scaffolds through the bulk medium. On the down stroke, medium is forced up through the scaffold pores. On the up stroke the direction of perfusion is reversed.

recovered, cut in half, and visually inspected for the distribution of the blue/purple product of MTT reduction. The reactor was operated at $37^{\circ} \mathrm{C}$ in a humidified $5 \% \mathrm{CO}_{2}$ cell culture incubator.

\section{Seeding efficiency and cell viability}

To assess seeding efficiency, after $15 \mathrm{~h}$ of operation as described above, scaffolds were retrieved from the bioreactor, rinsed with phosphate-buffered saline (PBS), blotted on tissue paper, and digested overnight in proteinase $\mathrm{K}$ solution $(1 \mathrm{mg} / \mathrm{mL}$ of proteinase $\mathrm{K}, 50 \mathrm{mM}$ Tris, $1 \mathrm{mM}$ EDTA, $1 \mathrm{mM}$ iodoacetamide, Sigma), along with reference samples of the initial cell suspension, containing known cell numbers. All samples were analyzed via the CyQUANT Cell Proliferation Assay Kit (Molecular Probes). Cell seeding efficiencies were calculated as the percentage of nucleic acid in the scaffolds relative to the amount of nucleic acid for the total number of cells loaded per scaffold.

Cellular viability within constructs following the seeding phase, or after an additional 19 days of culture in the T-CUP, was assessed using a Live/Dead Viability/Cytotoxicity Kit from Molecular Probes. Scaffolds were perfused with $0.3 \%$ collagenase solution for $45 \mathrm{~min}$, followed by perfusion with $0.05 \%-0.53 \mathrm{mM}$ trypsin-EDTA solution for a further $15 \mathrm{~min}$. Cells were recovered by centrifugation and labeled with $4 \mu \mathrm{M}$ ethidium homodimer-1 and $2 \mu \mathrm{M}$ calcein AM in PBS. Live (green fluorescence) and dead (red fluorescence) cell populations were determined using a FACSCalibur (Beckton Dickinson) flow cytometer. Gates were set using cells from a freshly trypsinized monolayer culture as a "live cell control," and cells from the same culture after incubation in $70 \%$ ethanol for $30 \mathrm{~min}$ as a "dead cell control."

\section{Generation of cartilaginous constructs}

Expanded bovine AC were transferred to the T-CUP and cultured within Polyactive ${ }^{\mathrm{TM}}$ scaffolds for 14 days (drive velocity of $1 \mathrm{~mm} / \mathrm{s}$ for the seeding phase, and of $0.4 \mathrm{~mm} / \mathrm{s}$ for the culture phase), in DMEM with the above defined culture supplements to which was added $10 \mathrm{ngmL}$ of TGF$\beta 3,10 \mu \mathrm{g} / \mathrm{mL}$ of insulin, and $0.1 \mathrm{mM}$ L-ascorbic acid-2phosphate, as previously described. ${ }^{22}$ Medium refreshment was after 3 days and twice a week thereafter. Constructs were then recovered, fixed, and paraffin embedded. Five-micron sections were stained with safranin $\mathrm{O}$ for sulfated glycosaminoglycans (GAG).

\section{Generation of osteoinductive grafts}

Freshly isolated bone marrow mononuclear cells were transferred to the T-CUP and cultured within hydroxyapatite ENGipore scaffolds for 19 days (drive velocity for seeding $1 \mathrm{~mm} / \mathrm{s}$ and $0.4 \mathrm{~mm} / \mathrm{s}$ during the culture phase), in $\alpha$-MEM with the above defined culture supplements to which was added $5 \mathrm{ng} / \mathrm{mL}$ of FGF-2, $10 \mathrm{nM}$ dexamethasone, and $0.1 \mathrm{mM}$ L-ascorbic acid-2-phosphate, as previously described. ${ }^{17} \mathrm{Me}-$ dium was changed after 5 days and twice a week thereafter. Constructs were then recovered and implanted ectopically into nude mice for a further 8 weeks. Explanted tissues were fixed overnight in formalin, decalcified, and paraffin embedded for histological sectioning. Ten-micron sections were stained with Mayer's hematoxylin and eosin Y.

\section{Statistics}

Numerical data are presented as the mean \pm standard erdard error of the mean. Unless otherwise stated, seeding efficiencies and viability were determined for a minimum of 5 scaffolds for each data point.

\section{RESULTS}

\section{Technical operation of the T-CUP bioreactor}

The T-CUP bioreactor allowed controlled perfusion of a cell suspension or culture medium directly through the scaffold pores. The velocity of the scaffolds that could be achieved, driven by the stepper motor, was in the range of $0.05 \mathrm{~mm} / \mathrm{s}$ to $7 \mathrm{~mm} / \mathrm{s}$, with a step size resolution of $0.005 \mathrm{~mm}$. Velocity profiles could be defined via a PC interface, thus allowing for a variety of perfusion regimens to be applied. Operational reliability of the bioreactor was tested in the context of long-term cultures for up to 21 days. These were conducted on multiple occasions without mechanical failure, medium leaking, or contamination.

\section{Cell seeding efficiency, uniformity, and cell viability}

We first aimed at determining a suitable perfusion regimen for seeding bovine AC into Polyactive ${ }^{\mathrm{TM}}$ scaffolds (Fig. 4a). A drive velocity of $0.1 \mathrm{~mm} / \mathrm{s}$ resulted in poor seeding efficiencies, with most cells settled at the T-CUP bottom. A velocity increase to $1 \mathrm{~mm} / \mathrm{s}$ enhanced the cell seeding efficiency, 

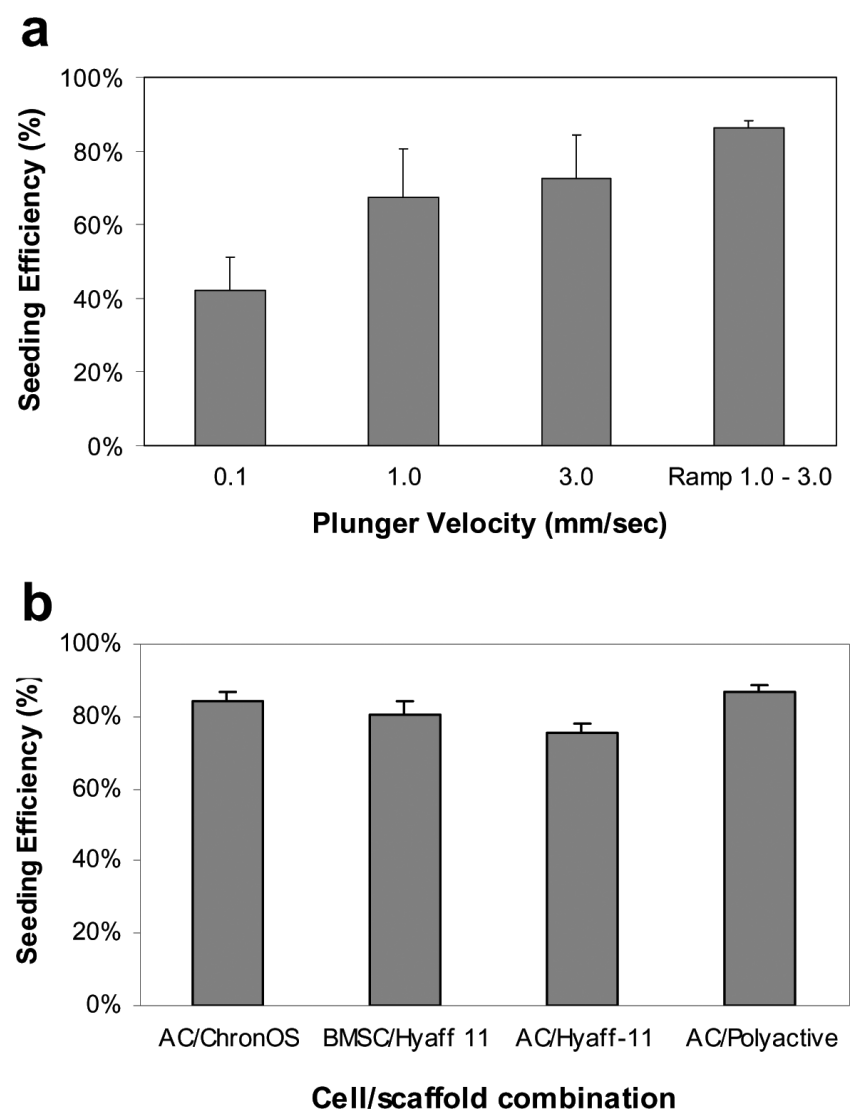

FIG. 4. Cell seeding efficiencies in the T-CUP bioreactor (a) using bovine articular chondrocytes (AC) and Polyactive ${ }^{\mathrm{TM}}$ foams at different velocity regimens, or (b) using different combinations of bovine AC and human bone marrow stromal cells (BMSC) on Polyactive $^{\mathrm{TM}}$, Hyaff ${ }^{\circledR}-11$, or chronOS ${ }^{\mathrm{TM}}$ disc-shaped scaffolds at the "Ramp 1.0-3.0" regimen (corresponding to a cyclic increase of the velocity from 1.0 to $3.0 \mathrm{~mm} / \mathrm{s}$ when the scaffold housing approaches the bottom of the vessel; see Results for a more detailed description).

but cells were still found at the bottom of the vessel. A further velocity increase to $3 \mathrm{~mm} / \mathrm{s}$ resolved the issue of cell settling but did not improve cell seeding efficiencies, likely owing to shear stress-induced cell damage. A ramped velocity profile was then tested to (1) prevent sedimentation of cells by generation of a mixing effect and (2) minimize cell damage due to continuous high-velocity flow: the drive velocity, set at $1 \mathrm{~mm} / \mathrm{s}$, was increased to $3 \mathrm{~mm} / \mathrm{s}$ when the scaffold housing approached the bottom of the culture vessel (i.e., starting at a $4 \mathrm{~mm}$ relative distance, corresponding to about $1 \mathrm{~s}$ out of a cycle time of about $20 \mathrm{~s}$ ), and then returned to $1 \mathrm{~mm} / \mathrm{s}$. This regimen resulted in reproducibly higher cell seeding efficiencies (Fig. 4a). Using the same velocity profile for other scaffold/cell type combinations, cell seeding efficiencies were always in excess of $75 \%$ (Fig. 4b), and cell viability within the scaffolds, as assessed following enzymatic extraction of the seeded cells, remained higher than 97\%. Im- portantly, cell seeding of the 6 individual constructs in the same experimental run was highly reproducible, with standard deviations for seeding efficiencies in the replicate scaffolds averaging $6.2 \% \pm 2.9 \%$.

MTT labeling of seeded Polyactive ${ }^{\mathrm{TM}}$ and Hyaff- $11^{\circledR}$ cylinders resulted in uniform staining (Fig. $5 b$ and c), indicating a uniform distribution of viable cells. ChronOS ${ }^{\mathrm{TM}}$ cylinders displayed a relatively less uniform cell distribution, although cells were well dispersed throughout the scaffold (Fig. 5d). The T-CUP bioreactor also allowed seeding of porous granules or fragments, using a basket configuration of the scaffold housing (Fig. 5e). Assessment of cell distribution indicated that for chronOS ${ }^{\mathrm{TM}}$ granules (Fig. 5f), all granules contained cells, although in larger granules a cell-free core was often observed. As for cylinders, a more uniform cell distribution was observed for Polyactive ${ }^{\mathrm{TM}}$ fragments (Fig. 5g), with cells penetrating to the core.

\section{Cartilaginous constructs}

To assess the potential of the T-CUP system to support cell differentiation, matrix deposition, and tissue maturation, Polyactive ${ }^{\mathrm{TM}}$ scaffolds seeded with bovine articular chondrocytes (AC) were further cultured under perfusion for a total of 14 days. The resulting tissues displayed abundant extracellular matrix rather uniformly distributed and positively stained for GAG (Fig. 6a). AC, which during expansion are known to de-differentiate, leading to a fibroblastic phenotype and elongated morphology, displayed in the generated tissues evidences of redifferentiation, with a typical spherical morphology and abundant pericellular matrix (Fig. 6b).

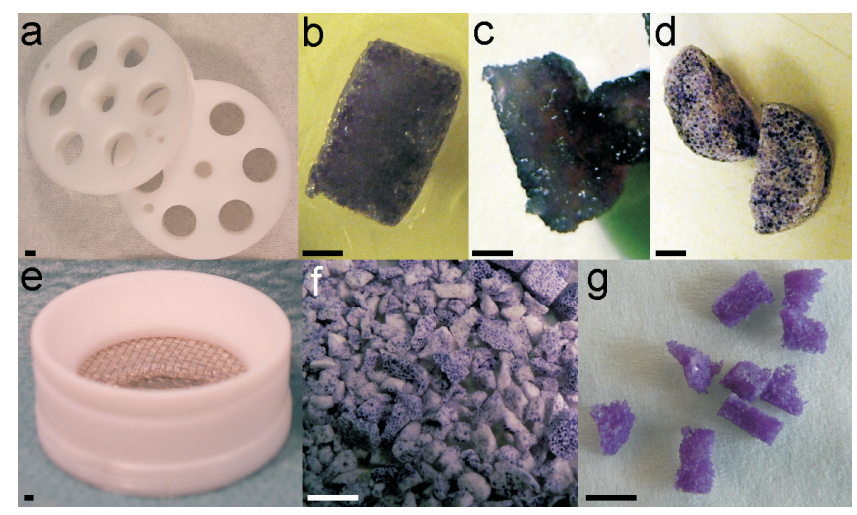

FIG. 5. Scaffold housing for (a) disc-shaped scaffolds or (e) granules/fragments, and MTT-labeled scaffolds after 15-h seeding of bovine articular chondrocytes into (b) Polyactive ${ }^{\mathrm{TM}}$ discs, (c) Hyaff ${ }^{\circledR}-11$ discs, (d) chronOS $^{\mathrm{TM}}$ discs, (e) chronOS $^{\mathrm{TM}}$ granules, and (f) Polyactive ${ }^{\mathrm{TM}}$ fragments in the T-CUP bioreactor. Purple/ blue color corresponds to the presence of viable cells. Scale bar is approximately $2 \mathrm{~mm}$. Color images available online at www .liebertpub.com/ten. 

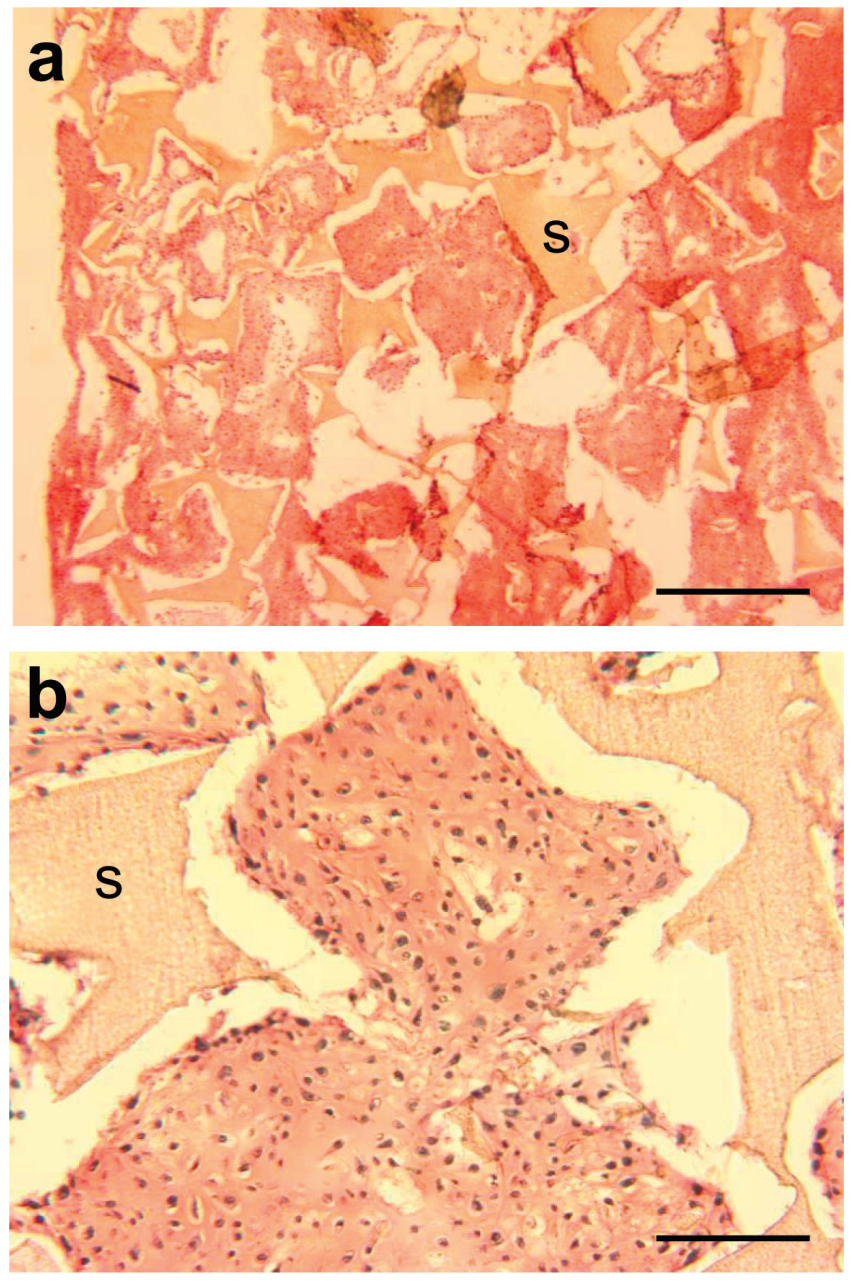

FIG. 6. Representative safranin-O stained sections of Polyactive $^{\mathrm{TM}}$ scaffolds loaded with bovine articular chondrocytes and cultured for 14 days in the T-CUP. Orange-red staining indicates the deposition of cartilaginous matrix containing sulfated glycosaminoglycans. The letter $s$ indicates parts of the undegraded scaffold. Scale bar $=400 \mu \mathrm{m}$ (a) and $100 \mu \mathrm{m}$ (b). Color images available online at www.liebertpub.com/ten.

\section{Osteoinductive grafts}

We next investigated whether the T-CUP bioreactor would allow generation of osteoinductive grafts by direct perfusion of bone marrow nucleated cells through ceramic scaffolds, according to a recently described method which bypasses bone marrow stromal cell (BMSC) expansion in monolayer. ${ }^{17}$ Freshly isolated bone marrow cells were seeded and cultured for 19 days within ENGipore scaffolds under perfusion, resulting in the attachment and expansion of viable BMSC $(84.5 \% \pm 0.2 \%$ viability $)$ directly within the scaffolds. After ectopic implantation of the generated constructs into nude mice, bone tissue formation was observed throughout the constructs in the form of typical "ossicles," indicating the osteoinductive property of the grafts (Fig. 7).

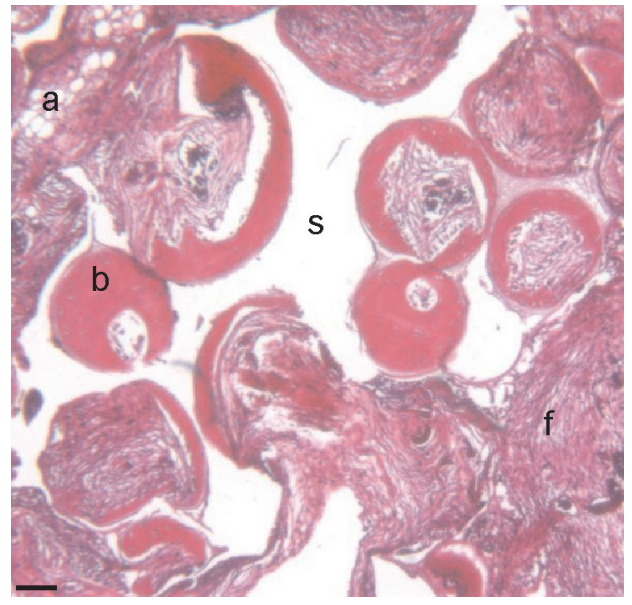

FIG. 7. Representative H\&E-stained section of ENGipore scaffolds loaded with human bone marrow nucleated cells, cultured for 19 days in the T-CUP, and implanted into nude mice for a further 8 weeks. Bone tissue (b) formation is apparent from the densely stained extracellular matrix observed within the scaffold (s) pores, in contrast to fibrous (f) or adipose (a) tissue. Scale bar $=100 \mu \mathrm{m}$. Color images available online at www.liebertpub.com/ten.

\section{DISCUSSION}

While direct perfusion is a promising approach to the seeding of cells onto 3D scaffolds and subsequent cultivation, there is a lack of simple, reliable, and efficient perfusion bioreactor systems with the flexibility to easily accommodate various scaffold types, geometries, and volumes. We have developed a simple to use bioreactor system, the T-CUP, that generates perfusion by movement of 3D scaffolds through a cell suspension or culture medium, and herein demonstrated that it is efficient, flexible, reliable, and effective.

The proposed bioreactor design offers several advantages over existing perfusion systems. First, the simple geometry of the T-CUP allows for rapid assembly and disassembly, with minimal risk of leakage resulting from a rarity of fittings. Second, by employing a stepper motor to drive scaffolds through the medium, precise control of the perfusion regimen can easily be achieved, whereas commonly used peristaltic pumps are prone to changing performance over time as tubes wear and stretch. The stepper motor also offers the possibility of tightly controlled ramped or stepped profiles and combinations of perfusion velocities, allowing for optimized cell/tissue-specific regimens with the same system. The importance of this feature was demonstrated in the phase of cell seeding, to reach reproducibly high seeding efficiencies. Third, the flexible configuration of the scaffold housing can accommodate scaffolds in a variety of numbers, sizes, and shapes with minimal changes in the system. The scaffold housing could allocate 6 discs, allowing reproducible replicate cultures in the same unit, could be made in the shape of a basket, allowing seeding of granule-shaped scaffolds, and indeed it could be entirely formed out of 
porous substrate, with - in the current T-CUP configurationa maximum diameter of $30 \mathrm{~mm}$ and maximum length of $30 \mathrm{~mm}$. Fourth, the T-CUP bioreactor provides the operational advantage of cell seeding and subsequent culture into a porous scaffold within the same reactor unit. A number of previously described perfusion bioreactor systems employ either static seeding of the scaffolds, ${ }^{23-29}$ or seeding in stirred flasks, ${ }^{30,31}$ before transfer of the seeded scaffold to the perfusion system. This additional handling increases labor requirements and the possibility of contamination. Alternative systems to seed and culture cells into scaffolds under perfusion require transit of cells across pump heads, ${ }^{10}$ which is generally detrimental to cell viability, or decoupling the flow paths of the seeding and culture phases, ${ }^{22}$ which is associated with complicated settings and increased contamination risks. Fifth, fluid flow through the scaffolds in the T-CUP bioreactor is inherently dynamic (i.e., in alternate directions at each cycle), as opposed to conventional steady-flow perfusion systems. This feature could be crucial for more uniform seeding and nutrition of cells in the scaffolds.

For human BMSC and bovine AC on several different scaffold types, efficiencies of 75-86\% (Fig. 4) were achieved with the T-CUP bioreactor. This is comparable to the efficiencies reported by Wendt et al. ${ }^{15}$ for a U-tube bioreactor employing alternating perfusion. Cells seeded in the T-CUP were distributed throughout cylindrical scaffolds (Fig. 5b-d), with viability near $100 \%$. The less uniform cell distribution observed within chronOS ${ }^{\mathrm{TM}}$ cylinders was most likely a consequence of scaffold architecture (e.g., relatively lower porosity).

In the case of chronOS ${ }^{\mathrm{TM}}$ granules (Fig. 5f), contact regions between individual granules and random open channels throughout the packed material are likely causes of a heterogeneous cell distribution. Considered as a whole, cells were well distributed throughout, and changes to packing and perfusion regimen are being investigated to improve distribution, penetration of cells into larger granules, and efficiency. Polyactive ${ }^{\mathrm{TM}}$ fragments seeded uniformly and with full penetration of cells into the scaffold, suggesting that fragments/granules of a more porous material might perform well without the need for specific optimization.

With its ease of use and high efficiency, the T-CUP could be an ideal bioreactor system for reliable and streamlined manufacture of grafts for clinical use. ${ }^{14}$ As a proof that the system can support cell differentiation, matrix deposition, and tissue maturation in vitro, we generated uniform cartilaginous tissues in a clinically relevant size (i.e., up to $4 \mathrm{~mm}$ thickness) starting from culture-expanded bovine articular chondrocytes. Further, as a demonstration that the system can streamline generation of tissues with the capacity to develop in vivo, we engineered osteoinductive constructs from freshly harvested human bone marrow cells, bypassing the phase of monolayer expansion of the mesenchymal component, in one single closed environment (Fig. 6). Further studies are required to investigate in the T-CUP system the effect of perfusion rate on cell differentiation and tissue growth, possibly combining experimental data with computational fluid dynamic and mass transport models. ${ }^{32}$

The T-CUP is currently being developed as a stand-alone system, with monitoring and control of relevant culture parameters, and including the feature of automated medium exchange, to provide a controlled and standardized "GMP in a box" environment. This would find application for the one-step manufacture of grafts starting from a patient biopsy in the field of clinical tissue engineering or for the automated expansion of cells within a 3D environment, for use in cell therapy and regenerative medicine. In its current configuration, the T-CUP bioreactor is an inherently simple, efficient, reliable, general- purpose system that can be used as a model to investigate the function of a variety of cell types in a 3D environment, using appropriate porous scaffolds as carriers.

\section{ACKNOWLEDGMENTS}

We acknowledge the efforts of Daniel Vonwil in testing an early prototype of the T-CUP, the craftsmanship of Karl Jakob in construction of the reactor vessel, and the contribution of Paulo Pereira and Dieter Cueni of INFORS AG for technical drawings of the T-CUP vessel and design of a stand-alone system. We thank IsoTis SV, Finceramica Faenza, Fidia Advanced Bioplolymers, and Synthes for the generous provision of scaffold materials and the Swiss Commission for Technology and Innovation (CTI) for partial funding of the work (Grant No. 7445.2).

\section{REFERENCES}

1. Burg, K.J., Delnomdedieu, M., Beiler, R.J., Culberson, C.R., Greene, K.G., Halberstadt, C.R., Holder, W.D., Jr., Loebsack, A.B., Roland, W.D., and Johnson, G.A. Application of magnetic resonance microscopy to tissue engineering: a polylactide model. J. Biomed. Mater. Res. 61, 380, 2002.

2. Kim, B.S., Putnam, A.J., Kulik, T.J., and Mooney, D.J. Optimizing seeding and culture methods to engineer smooth muscle tissue on biodegradable polymer matrices. Biotechnol. Bioeng. 57, 46, 1998.

3. Wendt, D., Jakob, M., and Martin, I. Bioreactor-based engineering of osteochondral grafts: from model systems to tissue manufacturing. J. Biosci. Bioeng. 100, 489, 2005.

4. Zhao, F., and Ma, T. Perfusion bioreactor system for human mesenchymal stem cell tissue engineering: dynamic cell seeding and construct development. Biotechnol. Bioeng. 91, 482, 2005.

5. Ishaug, S.L., Crane, G.M., Miller, M.J., Yasko, A.W., Yaszemski, M.J., and Mikos, A.G. Bone formation by threedimensional stromal osteoblast culture in biodegradable polymer scaffolds. J. Biomed. Mater. Res. 36, 17, 1997.

6. Bruinink, A., Siragusano, D., Ettel, G., Brandsberg, T., Brandsberg, F., Petitmermet, M., Muller, B., Mayer, J., and Wintermantel, E. The stiffness of bone marrow cell-knit composites is increased during mechanical load. Biomaterials 22, 3169, 2001. 
7. Ishaug-Riley, S.L., Crane-Kruger, G.M., Yaszemski, M.J., and Mikos, A.G. Three-dimensional culture of rat calvarial osteoblasts in porous biodegradable polymers. Biomaterials 19, 1405, 1998.

8. Sikavitsas, V.I., Bancroft, G.N., and Mikos, A.G. Formation of three-dimensional cell/polymer constructs for bone tissue engineering in a spinner flask and a rotating wall vessel bioreactor. J. Biomed. Mater. Res. 62, 136, 2002.

9. Carrier, R.L., Rupnick, M., Langer, R., Schoen, F.J., Freed, L.E., and Vunjak-Novakovic, G. Perfusion improves tissue architecture of engineered cardiac muscle. Tissue Eng. 8, 175, 2002.

10. Janssen, F.W., Oostra, J., Oorschot, A., and van Blitterswijk, C.A. A perfusion bioreactor system capable of producing clinically relevant volumes of tissue-engineered bone: in vivo bone formation showing proof of concept. Biomaterials 27, 315, 2006.

11. Li, Y., Ma, T., Kniss, D.A., Lasky, L.C., and Yang, S.T. Effects of filtration seeding on cell density, spatial distribution, and proliferation in nonwoven fibrous matrices. Biotechnol. Prog. 17, 935, 2001.

12. Xiao, Y.L., Riesle, J., and Van Blitterswijk, C.A. Static and dynamic fibroblast seeding and cultivation in porous PEO/ PBT scaffolds. J. Mater. Sci. Mater. Med. 10, 773, 1999.

13. Vunjak-Novakovic, G., Martin, I., Obradovic, B., Treppo, S., Grodzinsky, A.J., Langer, R., and Freed, L.E. Bioreactor cultivation conditions modulate the composition and mechanical properties of tissue-engineered cartilage. J. Orthop. Res. 17, 130, 1999.

14. Martin, I., Wendt, D., and Heberer, M. The role of bioreactors in tissue engineering. Trends Biotechnol. 22, 80, 2004.

15. Wendt, D., Marsano, A., Jakob, M., Heberer, M., and Martin, I. Oscillating perfusion of cell suspensions through threedimensional scaffolds enhances cell seeding efficiency and uniformity. Biotechnol. Bioeng. 84, 205, 2003.

16. Kim, S.S., Sundback, C.A., Kaihara, S., Benvenuto, M.S., Kim, B.S., Mooney, D.J., and Vacanti, J.P. Dynamic seeding and in vitro culture of hepatocytes in a flow perfusion system. Tissue Eng. 6, 39, 2000.

17. Braccini, A., Wendt, D., Jaquiery, C., Jakob, M., Heberer, M., Kenins, L., Wodnar-Filipowicz, A., Quarto, R., and Martin, I. Three-dimensional perfusion culture of human bone marrow cells and generation of osteoinductive grafts. Stem Cells 23, 1066, 2005.

18. Davisson, T., Sah, R.L., and Ratcliffe, A. Perfusion increases cell content and matrix synthesis in chondrocyte threedimensional cultures. Tissue Eng. 8, 807, 2002.

19. Hosseinkhani, H., Inatsugu, Y., Hiraoka, Y., Inoue, S., and Tabata, Y. Perfusion culture enhances osteogenic differentiation of rat mesenchymal stem cells in collagen sponge reinforced with poly(glycolic Acid) fiber. Tissue Eng. 11, 1476, 2005.

20. Gomes, M.E., Bossano, C.M., Johnston, C.M., Reis, R.L., and Mikos, A.G. In vitro localization of bone growth factors in constructs of biodegradable scaffolds seeded with marrow stromal cells and cultured in a flow perfusion bioreactor. Tissue Eng. 12, 177, 2006.
21. Jakob, M., Demarteau, O., Schafer, D., Hintermann, B., Dick, W., Heberer, M., and Martin, I. Specific growth factors during the expansion and redifferentiation of adult human articular chondrocytes enhance chondrogenesis and cartilaginous tissue formation in vitro. J Cell Biochem. 81, 368, 2001.

22. Wendt, D., Stroebel, S., Jakob, M., John, G.T., and Martin, I. Uniform tissues engineered by seeding and culturing cells in 3D scaffolds under perfusion at defined oxygen tensions. Biorheology 43, 481, 2006.

23. Bancroft, G.N., Sikavitsas, V.I., van den Dolder, J., Sheffield, T.L., Ambrose, C.G., Jansen, J.A., and Mikos, A.G. Fluid flow increases mineralized matrix deposition in $3 \mathrm{D}$ perfusion culture of marrow stromal osteoblasts in a dose-dependent manner. Proc. Natl. Acad. Sci. USA 99, 12600, 2002.

24. Holtorf, H.L., Sheffield, T.L., Ambrose, C.G., Jansen, J.A., and Mikos, A.G. Flow perfusion culture of marrow stromal cells seeded on porous biphasic calcium phosphate ceramics. Ann. Biomed. Eng. 33, 1238, 2005.

25. Holtorf, H.L., Jansen, J.A., and Mikos, A.G. Flow perfusion culture induces the osteoblastic differentiation of marrow stroma cell-scaffold constructs in the absence of dexamethasone. J. Biomed. Mater. Res A 72, 326, 2005.

26. Radisic, M., Euloth, M., Yang, L., Langer, R., Freed, L.E., and Vunjak-Novakovic, G. High-density seeding of myocyte cells for cardiac tissue engineering. Biotechnol. Bioeng. 82, 403, 2003.

27. Navarro, F.A., Mizuno, S., Huertas, J.C., Glowacki, J., and Orgill, D.P. Perfusion of medium improves growth of human oral neomucosal tissue constructs. Wound Repair Regen. 9, 507, 2001.

28. Cartmell, S.H., Porter, B.D., Garcia, A.J., and Guldberg, R.E. Effects of perfusion rate on cell-seeded three-dimensional bone constructs in vitro. Tissue Eng. 9, 1197, 2003.

29. Dvir, T., Benishti, N., Shachar, M., and Cohen, S. A novel perfusion bioreactor providing a homogeneous milieu for tissue regeneration. Tissue Eng. 12, 2843, 2006.

30. Mahmoudifar, N., and Doran, P.M. Tissue engineering of human cartilage in bioreactors using single and composite cell-seeded scaffolds. Biotechnol. Bioeng. 91, 338, 2005.

31. Mahmoudifar, N., and Doran, P.M. Tissue engineering of human cartilage and osteochondral composites using recirculation bioreactors. Biomaterials 26, 7012, 2005.

32. Porter, B., Zauel, R., Stockman, H., Guldberg, R., Fyhrie, D. 3-D computational modeling of media flow through scaffolds in a perfusion bioreactor. J. Biomech. 38, 543, 2005.

Address reprint requests to: Ivan Martin, Ph.D. Tissue Engineering, Laboratory 405 Institute for Surgical Research and Hospital Management Hebelstrasse 20 CH-4031 Basel Switzerland

E-mail: imartin@uhbs.ch 